Article

\title{
Dietary Vegetable Powders Modulate Immune Homeostasis and Intestinal Microbiota in Mice
}

\author{
Yixin Zou ${ }^{1,2}$, Haifei $\mathrm{Yu}^{2}$, Li Zhang ${ }^{2}$ (D) and Zheng Ruan ${ }^{1,2, *(D)}$ \\ 1 Beijing Advanced Innovation Center for Food Nutrition and Human Health, Beijing Technology and Business \\ University (BTBU), Beijing 100048, China; zyx_990812@163.com \\ 2 State Key Laboratory of Food Science and Technology, Institute of Nutrition and School of Food Science, \\ Nanchang University, Nanchang 330047, China; ffeiiii@163.com (H.Y.); zhangli@ncu.edu.cn (L.Z.) \\ * Correspondence: ruanzheng@ncu.edu.cn; Fax: +86-791-8827-2923
}

check for updates

Citation: Zou, Y.; Yu, H.; Zhang, L.; Ruan, Z. Dietary Vegetable Powders Modulate Immune Homeostasis and Intestinal Microbiota in Mice. Foods 2022, 11, 27. https://doi.org/ $10.3390 /$ foods 11010027

Academic Editor: Yiannis Kourkoutas

Received: 31 October 2021

Accepted: 20 December 2021

Published: 23 December 2021

Publisher's Note: MDPI stays neutral with regard to jurisdictional claims in published maps and institutional affiliations.

Copyright: (C) 2021 by the authors. Licensee MDPI, Basel, Switzerland. This article is an open access article distributed under the terms and conditions of the Creative Commons Attribution (CC BY) license (https:// creativecommons.org/licenses/by/ $4.0 /)$.

\begin{abstract}
As the largest immune organ of the human body, the intestine also plays a vital role in nutrient digestion and absorption. Some vegetables are considered to have improvement effects on the intestine. This experiment explored the effects of freeze-dried asparagus, broccoli and cabbage powder on the intestinal immune homeostasis and microflora of mice. Thirty-two mice were divided into four groups $(n=8)$, including control group (fed normal diet), asparagus group (fed normal diet with $5 \%$ asparagus power), broccoli group (fed normal diet with $5 \%$ broccoli power) and cabbage group (fed normal diet with $5 \%$ cabbage power). The experiment lasted 21 days. The results showed that the serum immunoglobulin concentration $(\operatorname{Ig} \mathrm{A}$ and $\operatorname{IgM})$ and intestinal cytokine content (like IFN- $\gamma$ and TNF- $\alpha$ ) were increased after vegetable powder supplement. The experiment also detected that vegetable powder supplementation changed intestinal flora and their metabolites (short-chain fatty acid), which showed that the abundance of Lachnospiraceae and Bacteroides were decreased, while the abundance of Firmicutes and Lactobacillus as well as propionic acid and butyric acid contents were increased. Together, these vegetable powders, especially cabbage, changed the intestinal immune response and microbial activity of mice.
\end{abstract}

Keywords: vegetables; freeze-drying; immunity; intestinal flora; polyphenols

\section{Introduction}

The intestine is the body's largest immune organ, as well as an important place for digestion and absorption of nutrients. In recent years, intestinal diseases have occurred more and more frequently, and the number of patients with colitis and colorectal adenoma is gradually increasing. In recent investigations of human cancers, colorectal cancer is increasing year by year in global incidence and has occupied the third position [1]. For this reason, maintaining a healthy gut is important. There is a special group of organisms that plays a very key role in the intestinal tract called "the intestinal flora", which contains about 10 trillion microorganisms [2]. These microorganisms form a symbiotic system with the intestinal tract and participate in a series of physiological processes such as digestion and immunity. Numerous studies have shown that intestinal microbes are closely related to the development of intestinal diseases, and some of them have been found to be involved in the deterioration of colorectal cancer (CRC), such as Fusobacteriumnuleatum, Escherichia coli, Bacteroides fragilis, campylobacter jejuni, etc. [3]. Other bacteria can delay the development of CRC by regulating immune response, improving intestinal barrier function and inhibiting cell proliferation. For example, Lactobacillus acidophilus and Bifidobacterium longum can increase the number of cell conjunctions, and Lactobacillus casei can reduce the heteromorphism of patients undergoing colorectal cancer resection [4]. Some bacteria that produce butyric acid can mediate immune system changes through metabolism to balance intestinal cell proliferation and death [5]. Studies over the years have shown that diet can improve the development of intestinal diseases through the intestinal flora. For example, a 
high-fiber diet can increase the abundance of Firmicutes in the intestinal tract, reduce the abundance of Bacteroidetes and increase the concentration of short-chain fatty acids, which can promote the effect of immunotherapy; nulin and fructose-oligosaccharides added to the human diet can stimulate the proliferation of bifidobacteria [6]. Inspired by this, we found some vegetables capable of protecting the intestine, such as cruciferous broccoli (Brassica oleracea var. italica) and cabbage (Brassica oleracea-Capitata Group). These kinds of vegetables are rich in vitamins and fiber, and can promote intestinal peristalsis and improve inflammation; they also contain glucosinolates, substances in the body after digestion that can enhance immune function and improve the balance of intestinal flora $[7,8]$. Asparagus (Asparagus officinalis) is also rich in dietary fiber and oligosaccharides; some of its active ingredients such as quercetin and rutin can affect the composition of colon microbes and play a certain role in reducing intestinal inflammation and injury [9]. As these three vegetables can improve the intestinal tract to some extent according to previous reports, we made asparagus, broccoli and cabbage into powder to explore the effects of dietary vegetable powder on the intestinal tract of mice, and to compare the effects of different vegetables. Hopefully our study can provide data support for the development of functional food to improve intestinal health by using these vegetables.

\section{Materials and Methods}

\subsection{Qualification of Average Daily Body Weight Gain (ADG) of Mice}

Animals, diet and experimental design. Procedures for animal experiments are shown in Figure 1. Thirty-two six-week-old KunMing mice were bought from Tian Qin Biotechnology (Changsha, China). All animals were fed in a controlled environment, with temperature $24 \pm 1{ }^{\circ} \mathrm{C}$, humidity $40-60 \%$, and $12 \mathrm{~h}$ daylight cycle. Then, the mice were randomly divided into 4 groups $(n=8)$ : normal control group, asparagus group, broccoli group and cabbage group. The normal control group was intragastric with normal saline and fed an ordinary diet every day, while the other three groups were fed an ordinary diet with $5 \%$ freeze-dried vegetable powder. The whole feeding process lasted for 21 days. The experiment was approved by the Animal Experimentation Ethical Committee of Nanchang University (permission number: 201800022). The feeding and operation of experimental animals were conducted in accordance with the experimental animal welfare ethical code of Nanchang University.

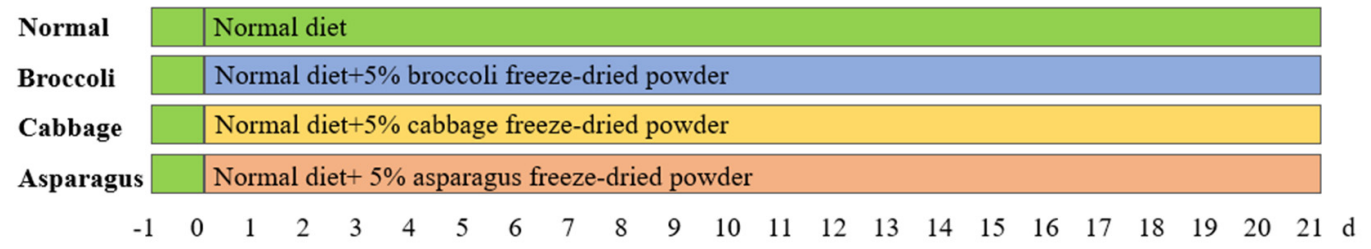

Figure 1. Experimental period diagram.

After 21 days of feeding, all mice fasted overnight. All mice were euthanized by carbon dioxide anesthesia followed by cervical dislocation, then we removed their intestinal tissue and collected blood and feces into separate EP tubes and stored in a $-80{ }^{\circ} \mathrm{C}$ refrigerator.

Weight measurement of mice. We weighed the mice in each group at a fixed time every day, and then calculated the average daily gain of mice.

\subsection{Determination of Immunoglobulin Concentration}

The concentrations of immunoglobulin A, G and M in mice serum were determined by double-antibody sandwich enzyme-linked immunosorbent assay (ELISA) referring to the method of Lindsey et al. with some modifications [10].

Serum sample collection. The blood of mice in each group was collected in the corresponding test tube, placed at room temperature for $2 \mathrm{~h}$, centrifuged at $3000 \mathrm{rpm}$ for $10 \mathrm{~min}$, and the supernatant was taken to obtain serum samples. 
ELISA determination. ELISA kits (Jiangsu Meimian Industrial Co., Ltd., Zhangjiagang, China) corresponding to IgA, IgG and IgM were taken out to prepare standard solution with concentration gradient for subsequent production of standard curves. We added the diluted standard solution from low to high concentration to the 96-well plate, then added the mice serum diluted with sample dilution to the next well; the amount of solution in each well was $100 \mu \mathrm{L}$. At the same time, we made two duplicate wells in the plate. We sealed the film plate slowly and shook the liquid evenly in the hole. After incubation for $2 \mathrm{~h}$ at $37^{\circ} \mathrm{C}$, the liquid in the well plate was removed, and then washed 2 3 times with washing solution; we carefully dried the liquid with filter paper. We added $100 \mu \mathrm{L}$ antibody with a pipette gun, incubated for $60 \mathrm{~min}$, added $100 \mu \mathrm{L}$ chromogenic substrate in a dark room, added the stop solution immediately after the appropriate color, observed the depth of color in the reaction hole, measured the OD value at $450 \mathrm{~nm}$ with a microplate analyzer and calculated the cytokine content in the serum of each group of mice.

\subsection{Determination of Intestinal Cytokine Concentration in Mice}

The concentrations of IL-1, IL-10, TNF- $\alpha$ and INF- $\gamma$ in the jejunum and ileum of mice were also determined by ELISA as previously described [11].

Collection of intestinal tissue samples. Jejunum and ileum tissues of mice in each group were taken $(200 \mathrm{mg}$ ) and ground in normal saline to prepare tissue homogenates. After centrifugation at $4{ }^{\circ} \mathrm{C}$ and $3000 \mathrm{rpm}$ for $10 \mathrm{~min}$, supernatant was taken and put into plastic tubes.

ELISA determination. The ELISA kits (Jiangsu Meimian Industrial Co., Ltd., Zhangjiagang, China) corresponding to IL-1, IL-10, TNF- $\alpha$ and INF- $\gamma$ were removed, and the same procedure was performed for each kit using the corresponding liquid. A pipetting gun was used to prepare a standard solution with a concentration gradient, and then a standard curve was produced.

We added the homogenate of intestinal tissue diluted with sample diluent to a 96-well plate at $100 \mu \mathrm{L}$ per well, then added $100 \mu \mathrm{L}$ corresponding secondary antibody to the well, shaking to make the liquid uniform. After incubation at $37^{\circ} \mathrm{C}$ for $1 \mathrm{~h}$, the washing solution was washed 2-3 times, adding $80 \mu \mathrm{L}$ affinity enzyme-HRP, incubating for $30 \mathrm{~min}$, adding $50 \mu \mathrm{L}$ color substrate A and B for color, adding the stop solution quickly after the appropriate color, observing the depth of color in the reaction hole and measuring the OD value at $450 \mathrm{~nm}$ with a microplate meter. The contents of cytokines in jejunum and ileum homogenates were calculated.

\subsection{Quantification of Short-Chain Fatty Acids (SCFAs)}

The concentrations of acetic acid, propionic acid and butyric acid in caecum were determined by gas chromatography as per Wang et al. [12].

Short-chain fatty acids were extracted from cecal chyme with $0.05 \%$ phosphoric acid [13], mixed evenly and shaken, and stood at room temperature for $20 \mathrm{~min}$. After centrifuging at $15,000 \mathrm{rpm}$ at $4{ }^{\circ} \mathrm{C}$ for $15 \mathrm{~min}$, the supernatant was passed through gas chromatography and a flame ionization detector. At the same time, the curve of acetic acid, propionic acid and butyric acid standard solution was made, and then the sample results were compared with the standard results to determine the content of each short-chain fatty acid.

\subsection{Determination of Intestinal Flora in Mice}

Referring to the determination method of Yang et al. [14], we used a high-throughput $16 S$ rRNA gene sequencing method to measure the intestinal flora of mice. The datasets generated for this study can be found in the National Center of Biotechnology Information (NCBI) Sequence Read Archive (SRA) database (NCBI BioProject PRJNA773049).

DNA extraction. To accurately weigh $200 \mathrm{mg}$ feces, we used a QIAamp DNA Stool Mini Kit (Qiagen, Hilden, Germany) and extracted the DNA according to kit instructions. 
MiSeq Illumina Sequencing. Primers 515F (5'-GTGCCAGCMGCCGCGGTAA-3') and 926R (5'-GGATACHVGGGTWTCTAAT) were used to determine the sequencing range in the V3 and V4 regions of rRNA. We then used a MiSeq PE250 instrument (Illumina, San Diego, CA, USA) to sequence the purified amplicon. After that, sequences were assigned to operational taxonomic units (OTUs) by UPARES at $97 \%$ similarity. The results were then analyzed for species classification and abundance, and the phylum level heat map of species composition, beta diversity analysis and two-dimensional plan of PCoA were drawn. At the same time, the differences in the number of microorganisms among groups were compared and a Venn diagram was drawn.

\subsection{Statistics Analysis}

The data obtained in this study were analyzed by SPSS statistical software 24.0. To compare the mean differences among the groups, one-way analysis of variance (ANOVA) was used. Differences were considered significant at $P<0.05$. All values are expressed as the mean \pm SD.

\section{Results}

\subsection{Calculation of the Average Daily Gain of Mice in Each Group}

The statistical average daily gain of mice in each group is detailed in Table 1. It can be seen that the average daily gain of mice in the normal control group was the largest, which was $0.855 \mathrm{~g}$. The daily weight gain of mice in the other three groups after feeding with freeze-dried vegetable powder decreased, and the descending order was cabbage group $>$ asparagus group > broccoli group; the average daily weight gain of mice in the cabbage group was only $0.737 \mathrm{~g}$. However, statistical analysis showed that there was no significant difference in weight loss among all groups.

Table 1. The average daily body weight gain (ADG) of mice in different groups.

\begin{tabular}{cc}
\hline Group & ADG $(\mathrm{g} /$ day) \\
\hline Control & $0.855 \pm 0.036$ \\
Asparagus & $0.816 \pm 0.039$ \\
Broccoli & $0.788 \pm 0.025$ \\
Cabbage & $0.737 \pm 0.043$ \\
\hline
\end{tabular}

Values are means with standard deviations $(n=8)$.

\subsection{Analysis of Immunoglobulin Concentration in Mice}

Table 2 shows the measured changes of immunoglobulin A, G and M in each group of mice. It is not difficult to see that compared with the control group, dietary vegetable powder supplementation changed the immunoglobulin content in the intestinal tract of mice, and the IgM and IgA concentrations of the three groups were increased. The average IgA concentration of the asparagus $(88.05 \mathrm{ng} / \mathrm{mL})$ and cabbage $(84.86 \mathrm{ng} / \mathrm{mL})$ feeding groups as well as the $\operatorname{lgM}$ concentration of the asparagus $(4.67 \mathrm{ng} / \mathrm{mL})$ and broccoli $(4.63 \mathrm{ng} / \mathrm{mL})$ feeding groups were significantly higher than the control group $(80.12 \mathrm{ng} / \mathrm{mL}$ and $4.28 \mathrm{ng} / \mathrm{mL}$, respectively); the IgA concentration of the broccoli feeding group increased to $93.21 \mathrm{ng} / \mathrm{mL}$, higher than the other three groups. Although the $\operatorname{lgM}$ concentration of the cabbage feeding group increased, the change was less obvious than that of the other two vegetable feeding groups. The concentrations of $\lg G$ in the four groups were not significantly different. 
Table 2. Effects of vegetable powder on serum immunoglobulin concentrations of mice.

\begin{tabular}{ccccc}
\hline Group & Control & Asparagus & Broccoli & Cabbage \\
\hline IgA, ng/mL & $80.12 \pm 0.82^{\mathrm{c}}$ & $88.05 \pm 1.21^{\mathrm{b}}$ & $93.21 \pm 1.05^{\mathrm{a}}$ & $84.86 \pm 0.93^{\mathrm{b}}$ \\
$\mathrm{IgG}, \mathrm{ng} / \mathrm{mL}$ & $813.45 \pm 9.83$ & $838.03 \pm 12.02$ & $823.11 \pm 9.84$ & $827.20 \pm 11.82$ \\
$\mathrm{IgM}, \mathrm{ng} / \mathrm{mL}$ & $8.56 \pm 0.15^{\mathrm{b}}$ & $9.34 \pm 0.14^{\mathrm{a}}$ & $9.26 \pm 0.08^{\mathrm{a}}$ & $8.87 \pm 0.13^{\mathrm{ab}}$
\end{tabular}

Values are means with standard deviations $(n=8)$. Means in the same row with different superscripts differ $(P<0.05)$.

\subsection{Analysis of Cytokine Concentration in Jejunum and Ileum of Mice}

To investigate the effect of freeze-dried vegetable powder on the intestinal tract of mice, we measured the concentration of cytokines in the jejunum and ileum of mice in each group. According to Table 3, in the jejunum the concentrations of IL-1 $(80.27 \mathrm{pg} / \mathrm{mL})$ and TNF- $\alpha(950.23 \mathrm{pg} / \mathrm{mL})$ were significantly increased and the concentrations of IL-10 $(1326.68 \mathrm{pg} / \mathrm{mL})$ were obviously decreased after asparagus feeding. At the same time, the concentration of IL-1 $(61.07 \mathrm{pg} / \mathrm{mL})$ decreased significantly after broccoli feeding. Compared with the control group, the concentration of IFN- $\gamma$ in mice fed with three vegetable powders increased significantly, and the concentration of IFN- $\gamma$ in the broccoli feeding group increased the most $(1131.92 \mathrm{pg} / \mathrm{mL})$. In the ileum, the concentrations of IFN- $\gamma$ and IL10 were significantly increased by asparagus feeding $(1066.44 \mathrm{pg} / \mathrm{mL}$ and $1338.77 \mathrm{pg} / \mathrm{mL}$, respectively), and the concentration of TNF- $\alpha$ was significantly increased by broccoli feeding $(928.09 \mathrm{pg} / \mathrm{mL})$. Meanwhile, IL-1 and TNF- $\alpha$ concentrations $(100.39 \mathrm{pg} / \mathrm{mL}$ and $829.00 \mathrm{pg} / \mathrm{mL}$, respectively) were significantly increased in the cabbage feeding group.

Table 3. Effects of vegetable powder on intestinal cytokine concentrations of mice.

\begin{tabular}{ccccc}
\hline Group & Control & Asparagus & Broccoli & Cabbage \\
\hline Jejunum, pg/mL & & & & \\
IL-1 & $69.02 \pm 1.17^{\mathrm{b}}$ & $80.27 \pm 1.47^{\mathrm{a}}$ & $61.07 \pm 1.61^{\mathrm{c}}$ & $68.84 \pm 1.23^{\mathrm{b}}$ \\
IL-10 & $1676.67 \pm 36.71^{\mathrm{a}}$ & $1326.68 \pm 17^{\mathrm{c}}$ & $1494.44 \pm 23.72^{\mathrm{b}}$ & $1589.64 \pm 23.35^{\mathrm{ab}}$ \\
TNF- $\alpha$ & $728.13 \pm 14.92^{\mathrm{b}}$ & $950.23 \pm 18.45^{\mathrm{a}}$ & $729.37 \pm 17.83^{\mathrm{b}}$ & $918.64 \pm 8.94^{\mathrm{a}}$ \\
IFN- $\gamma$ & $762.96 \pm 23.15^{\mathrm{c}}$ & $889.94 \pm 11.79^{\mathrm{b}}$ & $1131.92 \pm 18.49^{\mathrm{a}}$ & $1071.57 \pm 10.54^{\mathrm{a}}$ \\
Ileum, pg/mL & & & & \\
IL-1 & $65.39 \pm 2.71^{\mathrm{b}}$ & $70.62 \pm 1.47^{\mathrm{b}}$ & $68.37 \pm 1.69^{\mathrm{b}}$ & $100.39 \pm 1.41^{\mathrm{a}}$ \\
IL-10 & $1629.44 \pm 44.49^{\mathrm{a}}$ & $1338.77 \pm 19.50^{\mathrm{b}}$ & $1546.33 \pm 20.21^{\mathrm{a}}$ & $1228.75 \pm 24.14^{\mathrm{b}}$ \\
TNF- $\alpha$ & $713.17 \pm 13.56^{\mathrm{c}}$ & $762.04 \pm 14.36^{\mathrm{c}}$ & $928.09 \pm 16.00^{\mathrm{a}}$ & $829.00 \pm 13.79^{\mathrm{b}}$ \\
IFN- $\gamma$ & $735.64 \pm 6.64^{\mathrm{b}}$ & $1066.44 \pm 19.37^{\mathrm{a}}$ & $792.01 \pm 19.42^{\mathrm{b}}$ & $765.54 \pm 16.22^{\mathrm{b}}$ \\
\hline
\end{tabular}

Means in the same row with different superscripts differ $(P<0.05)$.

\subsection{Analysis of Short-Chain Fatty Acid Content in Cecum of Mice}

In order to study whether the intake of vegetable powder affected the intestinal flora of mice, the content of short-chain fatty acids in the intestinal tract of mice was also measured in this experiment, as shown in Table 4. Compared with the control group $(6.03 \mu \mathrm{mol} / \mathrm{g})$, the content of acetic acid in the cecum of asparagus and broccoli was slightly decreased $(4.67 \mu \mathrm{mol} / \mathrm{g}$ and $4.87 \mu \mathrm{mol} / \mathrm{g}$ respectively), and that of the cabbage feeding group was $6.40 \mu \mathrm{mol} / \mathrm{g}$. Although it was higher than that of the other two groups, there was no statistical difference in caecal acetic acid content in mice fed with the three vegetable powders compared with the control group. After cabbage feeding, the propionic acid content in mice $(3.59 \mu \mathrm{mol} / \mathrm{g})$ was obviously increased compared with other groups, and the butyric acid content in mice after the cabbage feeding group $(2.82 \mu \mathrm{mol} / \mathrm{g})$ was significantly increased compared with other groups. 
Table 4. Effects of vegetable powder on intestinal short-chain fatty acid concentrations of mice.

\begin{tabular}{ccccc}
\hline Group & Control & Asparagus & Broccoli & Cabbage \\
\hline Caecum, $\mu \mathrm{mol} / \mathrm{g}$ & & & & \\
Acetic acid & $6.03 \pm 0.36^{\mathrm{ab}}$ & $4.67 \pm 0.23^{\mathrm{b}}$ & $4.87 \pm 0.32^{\mathrm{b}}$ & $6.40 \pm 0.47^{\mathrm{a}}$ \\
Propionic acid & $1.70 \pm 0.20^{\mathrm{b}}$ & $2.00 \pm 0.14^{\mathrm{b}}$ & $2.02 \pm 0.18^{\mathrm{b}}$ & $3.59 \pm 0.33^{\mathrm{a}}$ \\
Butyric acid & $1.48 \pm 0.22^{\mathrm{b}}$ & $1.95 \pm 0.18^{\mathrm{ab}}$ & $2.16 \pm 0.38^{\mathrm{ab}}$ & $2.82 \pm 0.38^{\mathrm{a}}$ \\
\hline
\end{tabular}

Means in the same row with different superscripts differ $(P<0.05)$.

\subsection{Analysis of High-Throughput $16 S$ rRNA Gene Sequencing Results}

To compare whether the composition of intestinal flora caused differences among groups, the species distribution of intestinal flora of mice in each group was drawn into a Venn diagram, as shown in Figure 2A-D. As can be seen from Figure 2A-C, the types of intestinal flora of mice in the blank control group were more than those in the other three groups, with an average of more than 2000 kinds. In the three groups treated with vegetable powder, the types of intestinal flora not only decreased to only 1100-1500 kinds, but also changed after the mice were fed with vegetable powder. Only about 700 species of bacteria in each group were the same as those in the blank control group, but new species of bacteria that were not previously present in the blank control group appeared, especially after broccoli feeding; 792 new species of bacteria were detected that were different from the control group. Compared with the control group, as shown in Figure 2D, 256 species of new bacteria emerged after feeding with asparagus, which were different from the other three groups. Similarly, 256 and 178 species of new bacteria emerged after feeding with broccoli and cabbage, respectively, and the quantity of the same species of new bacteria that emerged after feeding with three groups of vegetable powder was 132.

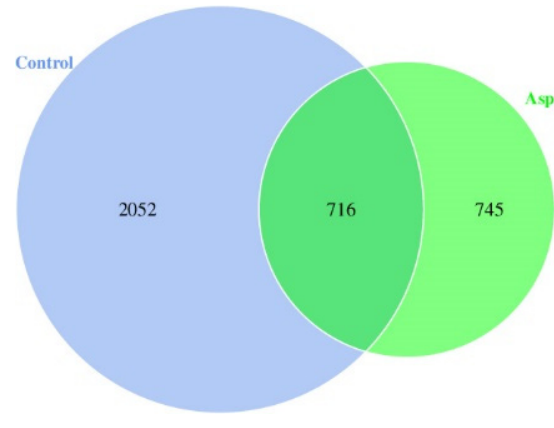

(A)

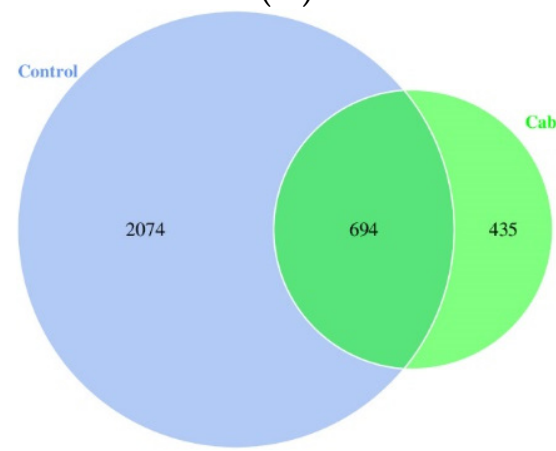

(C)

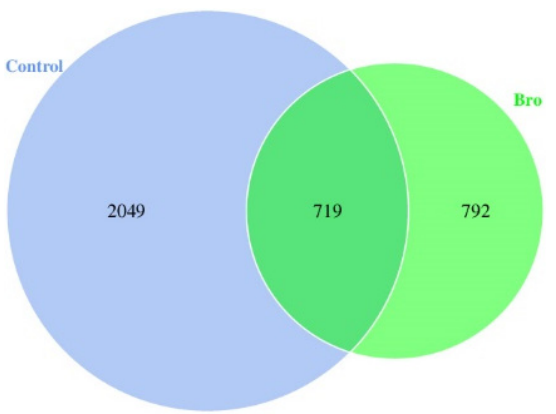

(B)

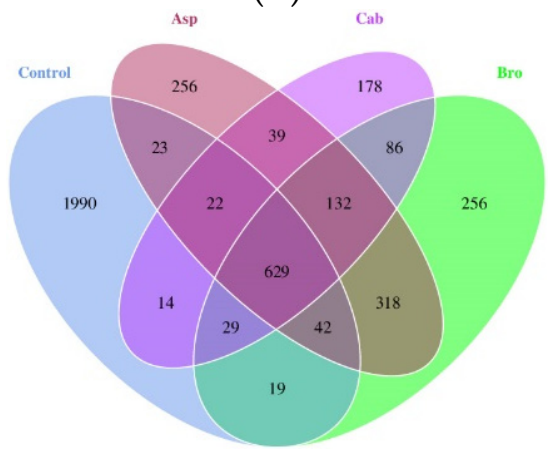

(D)

Figure 2. Venn diagram of intestinal flora species in mice. (A) Comparison of microflora abundance between control group and cabbage group; (B) comparison of microflora abundance between control group and broccoli group; (C) comparison of microflora abundance between control group and asparagus group; (D) comparison of microflora abundance between four groups. 
The results of beta diversity analysis are shown in Figure 3A,B. As can be seen from the two figures, the bacterial abundance of the blank control group was significantly different from that of the other three groups. The bacterial abundance of the other three groups after being fed with vegetable powder had a certain correlation, among which the bacterial abundance of the mice after being fed with asparagus and broccoli had a greater correlation, while the bacterial abundance of the cabbage group was slightly different.

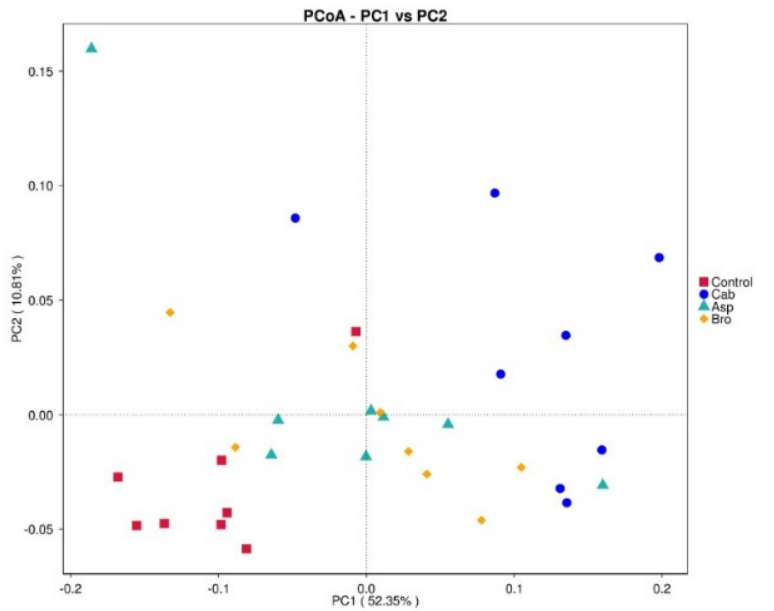

(A)

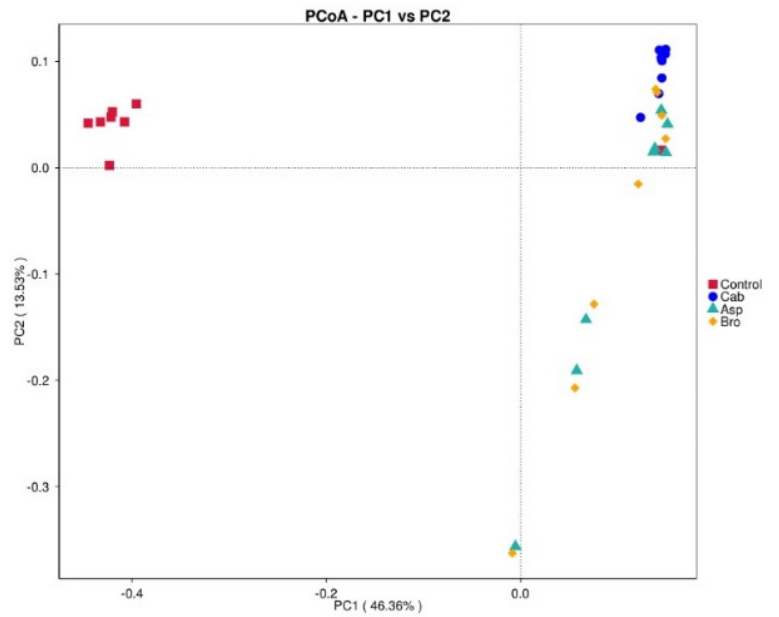

(B)

Figure 3. Correlation analysis diagram of intestinal flora species in each group of mice. (A) PCoA diagram of a certain angle; (B) PCoA diagram of another angle.

The thermal map of the horizontal composition of the microphyla in mice was further drawn, as shown in Figure 4. The differences in the composition of the microphyla in each group can be intuitively seen. As can be seen from the figure, the intestinal flora of mice are concentrated in the following six phyla: Actinobacteriota, Bacteroidota, Campilobacterota, Desulfobacterota, Firmicutes and Patescibacteria, and mostly Firmicutes, Bacteroidota followed. In the blank control group, bacteria genera with a high abundance in mice included Lachnospiraceae, Rubrobacter, Roseburia, Alistipes, Helicobacter, Bacteroides, Clostridia, etc. The genera with low abundance were Lachnoclostridium, Ruminococcus, Muribaculaceae and Desulfovibrio. In the heat map, the composition and abundance of the bacteria community after feeding with vegetable powder were significantly different from that of the control group. The abundances of bacteria with a higher abundance in the control group were almost all decreased in the three groups. For example, the abundances of several bacteria with higher abundances in the control group just mentioned were significantly decreased in the cabbage treatment group. In contrast, the low abundance of bacteria in the control group seemed to rebound after being fed with vegetable powder; for example, in the cabbage group, the abundance of Muribaculaceae, Desulfovibrio, Clostridium, Faecalibaculum, Prevotellaceae, Prevotella and Lactobacillus increased significantly. After broccoli treatment, the abundance of Eubacterium and Alloprevotella increased, while the abundance of Oscillibacter, Anaerotruncus and Lachnoclostridium increased obviously in the asparagus feeding group. 


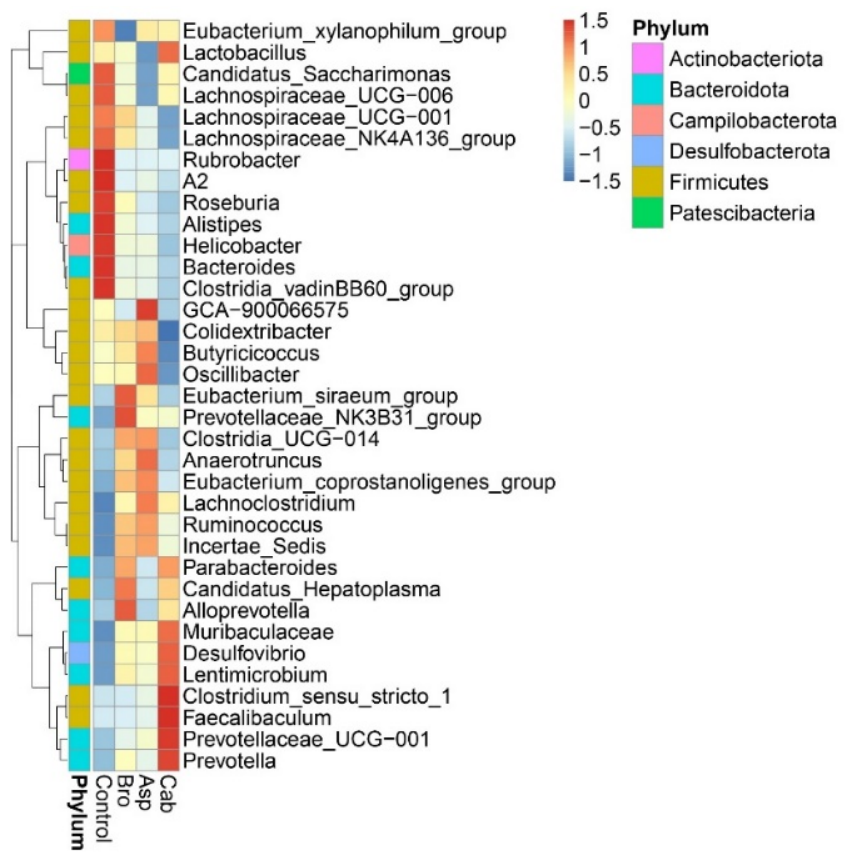

Figure 4. Heat map of intestinal flora abundance in mice.

\section{Discussion}

\subsection{Dietary Intake of Vegetable Powder Increased Immunoglobulin Concentration in Mice}

Brassica vegetables (cabbage and broccoli) have been reported to be a good source of many nutrients and phytochemicals that are effective in preventing the development of certain immune dysfunctional diseases [15]. In addition, Zhang et al. [16] showed that Lactobacillus plantarum NCU116 fermentation on Asparagus officinalis polysaccharide also had good immunomodulatory activity. Notably, immunoglobulins are the most widely used blood products in clinical practice due to their unique immunomodulatory and antiinflammatory activities [17]. Liu et al. [18] found that broccoli residues fermented with probiotics increased the levels of $\operatorname{Ig}$ A, Ig G and Ig M in the sera of C. perfringens-infected birds. Similarly, our results showed that broccoli, cabbage and asparagus powder all increased Ig A and Ig M levels in mice serum, but did not have a significant effect on Ig G levels (Table 2). In contrast to our experimental results, Miyazaki et al. [19] found that $1 \%$ fermented extract of cabbage was able to increase significantly the level of Ig G in the serum of rats. This may be due to the fact that fermentation alters the nutrient content of cabbage and thus its effect on immune function. One of the important components of the intestinal barrier function of the intestinal flora structure is the host secretory immune system, which limits opportunistic invasion by pathogenic members of the intestinal flora [20]. Ig A is specifically used for the protection of intestinal mucosa and is the most abundant antibody isotype in mucosal secretions [21]. Many reports have shown that prebiotics can maintain the homeostasis of the immune environment and improve intestinal barrier function by affecting the production and secretion of Ig A [22-24]. Importantly, our study found that broccoli, cabbage and asparagus powder were most effective in increasing serum Ig A levels compared to serum Ig G and Ig M levels. This suggests that dietary vegetable powders are promising candidates for prebiotics, which in turn regulate human intestinal immune homeostasis.

4.2. Dietary Intake of Vegetable Powder Changed the Concentration of Cytokines in the Jejunum and Ileum of Mice

Cytokines, including tumor necrosis factor (TNF), interleukins (ILs) and interferons (IFN), can affect the body by modulating the immune system, thereby regulating cell proliferation and repairing damaged tissue [25]. To further investigate the modulation of intestinal immune activity by vegetable powder, we measured the cytokines (IL-1, IL-10, 
TNF- $\alpha$, and INF- $\gamma$ ) secreted from the jejunum and the ileum of mice after consuming vegetable powder. In the present study, we found that the concentration of IL-1 was higher in the ileum in the cabbage group than that in the control group. This suggests that cabbage powder regulates the immune response in the ileum, which in turn is involved in the maintenance of immune homeostasis in the intestine [26]. IL-10 is an important immune regulator of many autoimmune diseases and inflammatory conditions [7]. Our results show that IL-10 concentrations in the jejunum of mice fed broccoli, cabbage and asparagus powder were significantly lower compared to controls. However, Hubbard et al. [9] suggested that dietary broccoli could reduce colitis and maintain intestinal environmental homeostasis in mice because broccoli protects the intestine by regulating aryl hydrocarbon receptor (AHR) activity. In addition, Power et al. [27] showed that dietary cooked asparagus was effective in reducing colonic inflammation and repairing colonic mucosal damage. In conclusion, vegetable powder has a moderating effect on maintaining the homeostasis of the intestinal environment. However, the mechanism of the interaction between the anti-inflammatory effect of vegetable powder on the intestinal tract and the immune response needs to be further investigated. IFN- $\gamma$ has anti-infective and anti-proliferative properties and is also a key regulator of immune cell activation [28,29]. Currently, some plant polysaccharides have been reported to demonstrate the superior ability to promote IFN- $\gamma$ secretion $[30,31]$. In addition, the results of this study demonstrate that broccoli, cabbage and asparagus powder all promoted the secretion of IFN- $\gamma$ in the jejunum of mice. This suggests that dietary vegetable powders can promote immunity by modulating inflammatory cytokines in the jejunum and ileum.

\subsection{Dietary Intake of Vegetable Powder Changed the Composition and Abundance of Intestinal Flora in Mice}

The balance of intestinal flora structure is considered to be an important factor affecting host health, and diet is the main determinant of intestinal flora composition. Dietary intake of fruits and vegetables has been reported to influence the composition of intestinal microorganisms [32]. In particular, it has been shown that cruciferous vegetables, like cabbage and broccoli, alter the composition of the human gut flora when consumed [33]. This study found that, compared to mice fed a normal diet, dietary cabbage powder increased the intestinal abundance of Muribaculaceae, Desulfovibrio, Clostridium, Faecalibaculum, Prevotellaceae, Prevotella and Lactobacillus abundance in the intestine of mice (Figure 4). The genera Muribaculaceae, Clostridium, Faecalibaculum and Prevotellaceae are all thought to be involved in the synthesis of SCFAs and to have a protective effect on the intestinal mucosal barrier [34-36]. Particularly, Clostridium is considered to be one of the important families of butyric acid producing bacteria [37], which is consistent with the above results. Prevotella is a bacterium that benefits the human intestine by promoting the release of inflammatory mediators from immune cells and various stromal cells [38,39]. Lactobacillus is known to be a probiotic that improves intestinal inflammation and protects the intestinal barrier [40,41]. In addition, $\mathrm{Mu}$ et al. [42] suggested that Lactobacillus was one of the reasons for the decrease in intestinal microflora in mice. As shown in Figure 2, the species of intestinal flora were significantly reduced in the cabbage group compared to the control group. Therefore, the decrease in intestinal flora species in mice fed cabbage powder may be associated with an increase in the abundance of Lactobacillus.

Broccoli and asparagus powder increased the abundance of Alloprevotella, Eubacterium, Oscillibacter, Anaerotruncus and Lachnoclostridium spp. in the intestine (Figure 4). Among them, Oscillibacter was able to promote the production of anti-inflammatory metabolites [43]. In addition, Alloprevotella is an efficient degrading bacterium of dietary fiber, which metabolizes dietary plant-derived polysaccharides into SCFAs [44]. Lachnoclostridium, Eubacterium and Anaerotruncus spp. can all be used as SCFA-producing bacteria, and both Eubacterium and Anaerotruncus spp. have been shown to be butyrate-producing bacteria in the human intestine [45-47]. This flora-regulating effect indicates that the vegetable powder has prebiotic properties. 
Admittedly, there are some limitations in this study that could be addressed in future research. First, only several cytokines and immunoglobulin were selected for determination in the experimental process because of the limitations of experimental design. This experiment was only to preliminarily explore the effects of freeze-dried powder of asparagus, broccoli and cabbage on the intestinal tract of mice. Although the measurement indexes were not comprehensive enough, the selected measurement indexes in the experiment were representative to some extent. Compared with the control group, the significant changes in these indexes could reflect that the intake of vegetable powder changed the intestinal immune environment of mice, which was also in line with our preliminary assumption. Finally, the influence and pathway of the active ingredients of vegetable powder on intestinal microbiota and its metabolites, and the effect and molecular mechanism of the active ingredients or microbiota-driven metabolites on the intestinal cells of the host need further research. Based on the results of this experiment, we need to take these limitations into account in the follow-up work and design a more perfect experimental scheme for further studying the specific action mechanism of vegetable powder on the intestinal tract of mice.

\section{Conclusions}

In conclusion, asparagus, broccoli and cabbage powder altered propionic and butyric acid contents, immunoglobulin concentrations (IgA and $\operatorname{IgM}$ ), cytokine concentrations (IL-1, TNF- $\alpha$, IFN- $\gamma$, IL-10) and microbial composition in mice. These results indicate that dietary vegetable powder may affect the immune homeostasis in the intestinal tract of mice and change the intestinal microflora of mice, which provides certain data support for the subsequent development of functional food or nutritional food rich in vegetable active ingredients.

Author Contributions: Writing-original draft preparation, Y.Z.; writing-review and editing, Z.R., L.Z., H.Y.; supervision, Z.R. All authors have read and agreed to the published version of the manuscript.

Funding: This work was supported by the Open Project of Beijing Advanced Innovation Center for Food Nutrition and Human Health (No. 20181050), the Key R \& D projects of Nanchang metropolis (No. 2019-NC2DSY-002) and the Key R \& D projects of Jiangxi Province (No. 20192ACB60006).

Institutional Review Board Statement: The animal study protocol was approved by the Animal Ethics Committee of Nanchang University (protocol code SYXK2020-0021 and 15 April 2020).

Data Availability Statement: The datasets generated for this study can be found in the National Center of Biotechnology Information (NCBI) Sequence Read Archive (SRA) database (NCBI BioProject PRJNA773049).

Conflicts of Interest: The authors declare that there are no conflict of interest.

\section{References}

1. Bray, F.; Ferlay, J.; Soerjomataram, I.; Siegel, R.L.; Torre, L.A.; Jemal, A. Global cancer statistics 2018: Globocan estimates of incidence and mortality worldwide for 36 cancers in 185 countries. CA Cancer J. Clin. 2018, 68, 394-424. [CrossRef] [PubMed]

2. Sender, R.; Fuchs, S.; Milo, R. Are We Really Vastly Outnumbered? Revisiting the Ratio of Bacterial to Host Cells in Humans. Cell 2016, 164, 337-340. [CrossRef] [PubMed]

3. Ren, L.; Ye, J.; Zhao, B.; Sun, J.; Cao, P.; Yang, Y. The Role of Intestinal Microbiota in Colorectal Cancer. Front. Pharmacol. 2021, 12, 674807. [CrossRef] [PubMed]

4. Cheng, Y.; Ling, Z.; Li, L. The Intestinal Microbiota and Colorectal Cancer. Front. Immunol. 2020, 11, 3100. [CrossRef] [PubMed]

5. Ding, S.; Xu, S.; Fang, J.; Jiang, H. The Protective Effect of Polyphenols for Colorectal Cancer. Front. Immunol. 2020, 11, 1407. [CrossRef]

6. Huang, P.; Liu, Y. A Reasonable Diet Promotes Balance of Intestinal Microbiota: Prevention of Precolorectal Cancer. BioMed Res. Int. 2019, 2019, 3405278. [CrossRef]

7. Hubbard, T.D.; Murray, I.A.; Nichols, R.; Cassel, K.; Podolsky, M.; Kuzu, G.; Tian, Y.; Smith, P.; Kennett, M.J.; Patterson, A.; et al. Dietary broccoli impacts microbial community structure and attenuates chemically induced colitis in mice in an Ah receptor dependent manner. J. Funct. Foods 2017, 37, 685-698. [CrossRef] 
8. Garcia-Ibañez, P.; Roses, C.; Agudelo, A.; Milagro, F.; Barceló, A.; Viadel, B.; Nieto, J.; Moreno, D.; Carvajal, M. The Influence of Red Cabbage Extract Nanoencapsulated with Brassica Plasma Membrane Vesicles on the Gut Microbiome of Obese Volunteers. Foods 2021, 10, 1038. [CrossRef]

9. Power, K.A.; Lu, J.T.; Monk, J.M.; Lepp, D.; Wu, W.; Zhang, C.; Liu, R.; Tsao, R.; Robinson, L.E.; Wood, G.A.; et al. Purified rutin and rutin-rich asparagus attenuates disease severity and tissue damage following dextran sodium sulfate-induced colitis. Mol. Nutr. Food Res. 2016, 60, 2396-2412. [CrossRef] [PubMed]

10. Lindsey, C.Y.; Pace-Templeton, J.G.; Millard, C.B.; Wannemacher, R.W.; Hewetson, J.F. Validation of ELISA for the determination of anti-ricin immunoglobulin G concentration in mouse sera. Biologicals 2006, 34, 33-41. [CrossRef]

11. Matsuda, T.; Hirano, T. Establishment of the ELISA for Murine-Soluble GP130, a Signal Transducer for the IL-6 Family Cytokine, and Its Detection in the Ascitic Fluids of Tumor-Bearing Mice. Biochem. Biophys. Res. Commun. 1994, 202, 637-642. [CrossRef] [PubMed]

12. Wan, J.; Hu, S.; Ni, K.; Chang, G.; Sun, X.; Yu, L. Characterisation of Fecal Soap Fatty Acids, Calcium Contents, Bacterial Community and Short-Chain Fatty Acids in Sprague Dawley Rats Fed with Different sn-2 Palmitic Triacylglycerols Diets. PLoS ONE 2016, 11, e0164894. [CrossRef]

13. Han, Y.; Song, M.; Gu, M.; Ren, D.; Zhu, X.; Cao, X.; Li, F.; Wang, W.; Cai, X.; Yuan, B.; et al. Dietary Intake of Whole Strawberry Inhibited Colonic Inflammation in Dextran-Sulfate-Sodium-Treated Mice via Restoring Immune Homeostasis and Alleviating Gut Microbiota Dysbiosis. J. Agric. Food Chem. 2019, 67, 9168-9177. [CrossRef] [PubMed]

14. Yang, Y.; Misra, B.; Liang, L.; Bi, D.; Weng, W.; Wu, W.; Cai, S.; Qin, H.; Goel, A.; Li, X.; et al. Integrated microbiome and metabolome analysis reveals a novel interplay between commensal bacteria and metabolites in colorectal cancer. Theranostics 2019, 9, 4101-4114. [CrossRef]

15. Francisco, M.; Tortosa, M.; Ballesta, M.M.; Velasco, P.; Garcia-Viguera, C.; Moreno, D. Nutritional and phytochemical value ofBrassicacrops from the agri-food perspective. Ann. Appl. Biol. 2016, 170, 273-285. [CrossRef]

16. Zhang, Z.-H.; Fan, S.-T.; Huang, D.-F.; Yu, Q.; Liu, X.-Z.; Li, C.; Wang, S.; Xiong, T.; Nie, S.-P.; Xie, M.-Y. Effect of Lactobacillus plantarum NCU116 Fermentation on Asparagus officinalis Polysaccharide: Characterization, Antioxidative, and Immunoregulatory Activities. J. Agric. Food Chem. 2018, 66, 10703-10711. [CrossRef]

17. Megha, K.; Mohanan, P. Role of immunoglobulin and antibodies in disease management. Int. J. Biol. Macromol. 2021, 169, 28-38. [CrossRef]

18. Liu, N.; Deng, X.; Liang, C.; Cai, H. Effect of Broccoli Residues Fermented with Probiotics on the Growth Performance and Health Status of Broilers Challenged with Clostridium perfringens. Braz. J. Poult. Sci. 2018, 20, 625-632. [CrossRef]

19. Miyazaki, Y.; Tokunaga, Y.; Takagaki, K.; Tsusaki, S.; Tachibana, H.; Yamada, K. Effect of Dietary Cabbage Fermentation Extract and Young Barley Leaf Powder on Immune Function of Sprague-Dawley Rats. J. Nutr. Sci. Vitaminol. 2001, 47, 253-257. [CrossRef]

20. Thursby, E.; Juge, N. Introduction to the human gut microbiota. Biochem. J. 2017, 474, 1823-1836. [CrossRef]

21. Gutzeit, C.; Magri, G.; Cerutti, A. Intestinal IgA production and its role in host-microbe interaction. Immunol. Rev. 2014, 260, 76-85. [CrossRef]

22. Vieira, A.T.; Teixeira, M.M.; Martins, F.D.S. The Role of Probiotics and Prebiotics in Inducing Gut Immunity. Front. Immunol. 2013, 4, 445. [CrossRef] [PubMed]

23. O'Flaherty, S.; Saulnier, D.; Pot, B.; Versalovic, J. How can probiotics and prebiotics impact mucosal immunity? Gut Microbes 2010, 1, 293-300. [CrossRef]

24. Liu, Z.; Xing, J.; Zheng, S.; Bo, R.; Luo, L.; Huang, Y.; Niu, Y.; Li, Z.; Wang, D.; Hu, Y.; et al. Ganoderma lucidum polysaccharides encapsulated in liposome as an adjuvant to promote Th1-bias immune response. Carbohydr. Polym. 2016, 142, 141-148. [CrossRef]

25. Mantovani, A.; Dinarello, C.A.; Molgora, M.; Garlanda, C. Interleukin-1 and Related Cytokines in the Regulation of Inflammation and Immunity. Immunity 2019, 50, 778-795. [CrossRef]

26. Lee, Y.M.; Shin, D.W.; Lim, B.O. Chlorogenic Acid Improves Symptoms of Inflammatory Bowel Disease in Interleukin-10 Knockout Mice. J. Med. Food 2020, 23, 1043-1053. [CrossRef] [PubMed]

27. Yoo, H.J.; Byun, H.-J.; Kim, B.-R.; Lee, K.H.; Park, S.-Y.; Rho, S.B. DAPk1 inhibits NF-kB activation through TNF- $\alpha$ and INF- $\gamma$-induced apoptosis. Cell. Signal. 2012, 24, 1471-1477. [CrossRef]

28. Gupta, K.K.; Khan, M.A.; Singh, S.K. Constitutive Inflammatory Cytokine Storm: A Major Threat to Human Health. J. Interf. Cytokine Res. 2020, 40, 19-23. [CrossRef] [PubMed]

29. Chen, X.; Cai, B.; Wang, J.; Sheng, Z.; Yang, H.; Wang, D.; Chen, J.; Ning, Q. Mulberry leaf-derived polysaccharide modulates the immune response and gut microbiota composition in immunosuppressed mice. J. Funct. Foods 2021, 83, 104545. [CrossRef]

30. Ding, Y.; Yan, Y.; Chen, D.; Ran, L.; Mi, J.; Lu, L.; Jing, B.; Li, X.; Zeng, X.; Cao, Y. Modulating effects of polysaccharides from the fruits of Lycium barbarumon the immune response and gut microbiota in cyclophosphamide-treated mice. Food Funct. 2019, 10, 3671-3683. [CrossRef]

31. Hua, M.; Liu, Z.; Sha, J.; Li, S.; Dong, L.; Sun, Y. Effects of ginseng soluble dietary fiber on serum antioxidant status, immune factor levels and cecal health in healthy rats. Food Chem. 2021, 365, 130641. [CrossRef]

32. Luo, J.; Lin, X.; Bordiga, M.; Brennan, C.; Xu, B. Manipulating effects of fruits and vegetables on gut microbiota-A critical review. Int. J. Food Sci. Technol. 2021, 56, 2055-2067. [CrossRef]

33. Li, F.; Hullar, M.A.J.; Schwarz, Y.; Lampe, J.W. Human Gut Bacterial Communities Are Altered by Addition of Cruciferous Vegetables to a Controlled Fruit- and Vegetable-Free Diet. J. Nutr. 2009, 139, 1685-1691. [CrossRef] 
34. Zagato, E.; Pozzi, C.; Bertocchi, A.; Schioppa, T.; Saccheri, F.; Guglietta, S.; Fosso, B.; Melocchi, L.; Nizzoli, G.; Troisi, J.; et al. Endogenous murine microbiota member Faecalibaculum rodentium and its human homologue protect from intestinal tumour growth. Nat. Microbiol. 2020, 5, 511-524. [CrossRef]

35. Ma, Y.; Jiang, S.; Zeng, M. In vitro simulated digestion and fermentation characteristics of polysaccharide from oyster (Crassostrea gigas), and its effects on the gut microbiota. Food Res. Int. 2021, 149, 110646. [CrossRef] [PubMed]

36. Yachida, S.; Mizutani, S.; Shiroma, H.; Shiba, S.; Nakajima, T.; Sakamoto, T.; Watanabe, H.; Masuda, K.; Nishimoto, Y.; Kubo, M.; et al. Metagenomic and metabolomic analyses reveal distinct stage-specific phenotypes of the gut microbiota in colorectal cancer. Nat. Med. 2019, 25, 968-976. [CrossRef]

37. Leylabadlo, H.E.; Ghotaslou, R.; Feizabadi, M.M.; Farajnia, S.; Moaddab, S.Y.; Ganbarov, K.; Khodadadi, E.; Tanomand, A.; Sheykhsaran, E.; Yousefi, B.; et al. The critical role of Faecalibacterium prausnitzii in human health: An overview. Microb. Pathog. 2020, 149, 104344. [CrossRef] [PubMed]

38. Rui, Y.; Wan, P.; Chen, G.; Xie, M.; Sun, Y.; Zeng, X.; Liu, Z. Simulated digestion and fermentation in vitro by human gut microbiota of intra- and extra-cellular polysaccharides from Aspergillus cristatus. LWT 2019, 116, 108508. [CrossRef]

39. Chen, D.; Ding, Y.; Chen, G.; Sun, Y.; Zeng, X.; Ye, H. Components identification and nutritional value exploration of tea (Camellia sinensis L.) flower extract: Evidence for functional food. Food Res. Int. 2020, 132, 109100. [CrossRef]

40. Xia, Y.; Chen, Y.; Wang, G.; Yang, Y.; Song, X.; Xiong, Z.; Zhang, H.; Lai, P.; Wang, S.; Ai, L. Lactobacillus plantarum AR113 alleviates DSS-induced colitis by regulating the TLR4/MyD88/NF-kB pathway and gut microbiota composition. J. Funct. Foods 2020, 67, 103854. [CrossRef]

41. Ren, Q.; Yang, B.; Zhang, H.; Ross, R.; Stanton, C.; Chen, H.; Chen, W. c9, t11, c15-CLNA and t9, t11, c15-CLNA from Lactobacillus plantarum ZS2058 Ameliorate Dextran Sodium Sulfate-Induced Colitis in Mice. J. Agric. Food Chem. 2020, 68, 3758-3769. [CrossRef]

42. Mu, Z.; Yang, Y.; Xia, Y.; Wang, F.; Sun, Y.; Yang, Y.; Ai, L. Probiotic yeast BR14 ameliorates DSS-induced colitis by restoring the gut barrier and adjusting the intestinal microbiota. Food Funct. 2021, 12, 8386-8398. [CrossRef]

43. Arivarasu, N.; Priyamvada, S.; Mahmood, R. Oral administration of caffeic acid ameliorates the effect of cisplatin on brush border membrane enzymes and antioxidant system in rat intestine. Exp. Toxicol. Pathol. 2013, 65, 21-25. [CrossRef] [PubMed]

44. Simpson, H.L.; Campbell, B.J. Review article: Dietary fibre-microbiota interactions. Aliment. Pharmacol. Ther. 2015, 42, 158-179. [CrossRef]

45. Schwiertz, A.; Lehmann, U.; Jacobasch, G.; Blaut, M. Influence of resistant starch on the SCFA production and cell counts of butyrate-producing Eubacterium spp. in the human intestine. J. Appl. Microbiol. 2002, 93, 157-162. [CrossRef] [PubMed]

46. Yuan, G.; Tan, M.; Chen, X. Punicic acid ameliorates obesity and liver steatosis by regulating gut microbiota composition in mice. Food Funct. 2021, 12, 7897-7908. [CrossRef]

47. Zhao, Q.; Hou, D.; Fu, Y.; Xue, Y.; Guan, X.; Shen, Q. Adzuki Bean Alleviates Obesity and Insulin Resistance Induced by a High-Fat Diet and Modulates Gut Microbiota in Mice. Nutrient 2021, 13, 3240. [CrossRef] [PubMed] 